\title{
Regulation of MMP13 by antitumor microRNA-375 markedly inhibits cancer cell migration and invasion in esophageal squamous cell carcinoma
}

\author{
YUSAKU OSAKO $^{1}$, NAOHIKO SEKI ${ }^{2}$, YOSHIAKI KITA ${ }^{1}$, KEIICHI YONEMORI ${ }^{1}$, KEIICHI KOSHIZUKA ${ }^{2}$, \\ AKIRA KUROZUMI $^{2}$, ITARU OMOTO ${ }^{1}$, KEN SASAKI ${ }^{1}$, YASUTO UCHIKADO ${ }^{1}$, \\ HIROSHI KURAHARA ${ }^{1}$, KOSEI MAEMURA ${ }^{1}$ and SHOJI NATSUGOE ${ }^{1}$ \\ ${ }^{1}$ Department of Digestive Surgery, Breast and Thyroid Surgery, Graduate School of Medical Sciences, \\ Kagoshima University, Sakuragaoka, Kagoshima 890-8520; ${ }^{2}$ Department of Functional Genomics, \\ Chiba University Graduate School of Medicine, Chuo-ku, Chiba 260-8670, Japan
}

Received August 8, 2016; Accepted September 28, 2016

DOI: $10.3892 /$ ijo.2016.3745

\begin{abstract}
Esophageal squamous cell carcinoma (ESCC) is one of the most aggressive malignancies. Recently developed molecular targeted therapies are not available for patients with ESCC. After curative surgical resection, patients frequently suffer distant metastasis and recurrence. Exploration of novel ESCC metastatic pathways may lead to the development of new treatment protocols for this disease. Accordingly, we have sequentially identified microRNA (miRNA)-mediated metastatic pathways in several cancers. Our past studies of miRNA expression signatures have shown that microRNA-375 (miR-375) is frequently reduced in several types of cancers, including ESCC. In the present study, we aimed to investigate novel $m i R$-375-mediated metastatic pathways in ESCC cells. The expression of $m i R-375$ was downregulated in ESCC tissues, and ectopic expression of this miRNA markedly inhibited cancer cell migration and invasion, suggesting that $m i R-375$ acted as an antimetastatic miRNA in ESCC cells. Our strategies for miRNA target searching demonstrated that matrix metalloproteinase 13 (MMP13) was directly regulated by $m i R-375$ in ESCC cells. Overexpression of MMP13 was observed in ESCC clinical tissues, and the expression of $M M P 13$ promoted cancer cell aggressiveness. Moreover, oncogenic genes, including $C E N P F, K I F 14$ and TOP $2 A$, were shown to be regulated downstream of MMP13. Taken together, these findings demonstrated that the antitumor $\mathrm{miR}$-375/oncogenic MMP13 axis had a pivotal role in ESCC aggressiveness.
\end{abstract}

Correspondence to: Dr Naohiko Seki, Department of Functional Genomics, Chiba University Graduate School of Medicine, 1-8-1 Inohana, Chuo-ku, Chiba 260-8670, Japan

E-mail: naoseki@faculty.chiba-u.jp

Key words: microRNA, miR-375, esophageal squamous cell carcinoma, matrix metalloproteinase 13 , tumor suppressor
These results provide novel insights into the potential mechanisms of ESCC pathogenesis.

\section{Introduction}

Esophageal squamous cell carcinoma (ESCC) is one of the most aggressive cancers and the major histological type of esophageal cancer in Japan and East Asia (1-3). ESCC cells frequently metastasize to the lymph nodes, liver, lungs and bone (2-4). Despite the use of multimodality therapies, the prognosis of patients with ESCC is still poor, with an overall 5-year survival rate of approximately $20-30 \%(2,4)$. Recently developed molecularly targeted therapeutics have not been shown to have beneficial effects in patients with ESCC (2). Additionally, the molecular pathogenesis of the aggressive phenotype in ESCC remains unclear. Thus, in order to improve disease outcomes in patients with ESCC, it is necessary to elucidate the molecular mechanisms of ESCC cell aggressiveness using advanced genomic approaches.

The discovery of microRNAs (miRNAs) has resulted in major advancements in cancer research $(5,6)$. miRNAs are small non-coding RNAs that function to fine tune the expression of protein coding/non-coding RNAs by repressing translation or cleaving RNA transcripts in a sequencedepending manner (7). The unique characteristic function of miRNAs is to regulate RNA transcripts in human cells. Therefore, dysregulated expression of miRNAs can disrupt tightly regulated RNA networks in cancer cells. Currently, numerous studies have shown that miRNAs are aberrantly expressed in several cancers, including ESCC $(6,8)$. Using miRNA expression signature analyses, we have sequentially identified tumor-suppressive miRNAs and shown that these miRNAs mediate novel cancer networks (9-13).

Our miRNA expression signatures revealed that microRNA-375 ( $m i R-375)$ is frequently downregulated in several types of squamous cell carcinoma $(10,13,14)$. Moreover, our previous studies demonstrated that ectopic expression of $m i R-375$ suppressed cancer cell aggressiveness in several types of cancer cells (15). In ESCC cells, several studies have 
Table I. Clinical features of patients with ESCC.

\begin{tabular}{rcllcllllll}
\hline No. & Age (years) & Gender & Differentiation & T & N & M & Stage & ly & v & Recurrence \\
\hline 1 & 68 & Male & Poor & $1 \mathrm{~b}$ & 2 & 0 & IIIA & 1 & 3 & + \\
2 & 72 & Male & Moderate & $1 \mathrm{~b}$ & 0 & 0 & IA & 0 & 1 & - \\
3 & 69 & Male & Moderate & $1 \mathrm{~b}$ & 0 & 0 & IIIA & 0 & 0 & - \\
4 & 62 & Male & Well & 3 & 2 & 0 & IIIB & 1 & 1 & + \\
5 & 66 & Male & Moderate & 3 & 0 & 0 & IIA & 1 & 1 & - \\
6 & 74 & Male & Moderate & 2 & 2 & 0 & IIIA & 3 & 1 & + \\
7 & 56 & Male & Moderate & 2 & 0 & 0 & IB & 0 & 1 & - \\
8 & 79 & Male & Moderate & 2 & 1 & 0 & IIB & 1 & 1 & - \\
9 & 68 & Male & Moderate & $1 \mathrm{~b}$ & 2 & 0 & IIIA & 1 & 1 & - \\
10 & 52 & Male & Poor & $1 \mathrm{~b}$ & 0 & 0 & IA & 1 & 1 & + \\
11 & 67 & Male & Well & 3 & 2 & 0 & IIIB & 2 & 2 & + \\
12 & 57 & Male & Poor & 3 & 3 & 0 & IIIC & 1 & 1 & + \\
13 & 70 & Male & Moderate & 3 & 0 & 0 & IIA & 1 & 1 & + \\
14 & 66 & Male & Moderate & 3 & 0 & 0 & IIA & 1 & 1 & - \\
15 & 63 & Male & Well & 3 & 3 & 0 & IIIC & 2 & 1 & + \\
16 & 55 & Male & Moderate & 3 & 2 & 0 & IIIB & 1 & 1 & + \\
17 & 60 & Male & Well & $1 \mathrm{~b}$ & 1 & 0 & IIB & 1 & 1 & - \\
18 & 78 & Male & Well & 3 & 0 & 0 & IIA & 1 & 2 & - \\
19 & 71 & Male & Well & 3 & 0 & 0 & IIA & 1 & 2 & - \\
20 & 75 & Male & Moderate & 3 & 2 & 0 & IIIB & 1 & 1 & + \\
21 & 60 & Male & Moderate & 2 & 1 & 0 & IIB & 1 & 2 & - \\
22 & 62 & Male & Well & $1 \mathrm{a}$ & 1 & 0 & IIB & 0 & 0 & - \\
23 & 71 & Male & Moderate & $1 \mathrm{~b}$ & 1 & 0 & IIB & 0 & 0 & - \\
24 & 69 & Male & Moderate & $1 \mathrm{~b}$ & 0 & 0 & IA & 1 & 0 & - \\
25 & 84 & Male & Well & 2 & 1 & 0 & IIB & 1 & 1 & - \\
\hline
\end{tabular}

indicated that $m i R-375$ has antitumor roles through targeting oncogenic genes $(16,17)$. Moreover, $m i R$-375-mediated cancer pathways are essential for cancer cell initiation, development and aggressiveness.

Accordingly, in the present study, we aimed to investigate the novel cancer networks regulated by $m i R-375$ in ESCC cells. Our present data showed that matrix metalloproteinase 13 (MMP13) was directly regulated by $m i R-375$ in ESCC cells. Overexpression of MMP13 was observed in ESCC clinical tissues, and knockdown of MMP13 expression markedly inhibited ESCC cell migration and invasion, indicating that $M M P 13$ acted as a cancer-promoting gene in ESCC cells. Moreover, the oncogenic genes $C E N P F, K I F 14$ and TOP 2 were found to function downstream of $M M P 13$. Taken together, these results showed that the antitumor $m i R-375 /$ oncogenic $M M P 13$ axis had a pivotal role in ESCC aggressiveness.

\section{Materials and methods}

Clinical ESCC specimens and ESCC cell lines. Clinical specimens were collected from 25 patients with ESCC. All patients underwent primary surgical treatment and were pathologically proven to have ESCC at the Kagoshima University Hospital from 2010 to 2014. The present study was approved by the Bioethics Committee of Kagoshima University; written prior informed consent and approval were obtained from all patients. The clinicopathological characteristics of the patients are shown in Table I.

We used two ESCC cell lines: TE-8, which was moderately differentiated; and TE-9, which was poorly differentiated. Both of these cells lines were provided by Riken BioResourse Center (Tsukuba, Japan).

Extraction of total RNA from clinical specimens and cell lines was performed using ISOGEN (Nippon Gene, Tokyo, Japan) according to the manufacturer's protocol. The quality of RNA was checked using an Agilent 2100 Bioanalyzer (Agilent Technologies, Santa Clara, CA, USA).

Quantitative real-time reverse transcription polymerase chain reaction ( $q R T-P C R$ ). The procedure for PCR quantification was previously described $(13,18-20)$. The expression levels of miR-375 (assay ID: 000564; Applied Biosystems, Foster City, CA, USA) were analyzed by TaqMan qRT-PCR assays (TaqMan MicroRNA assays; Applied Biosystems) and RNU48 (assay ID: 001006) was used for normalization. TaqMan probes and primers for $M M P-13$ (assay ID: Hs00233992_m1; Applied Biosystems), CENPF (assay ID: Hs01118845_m1), KIF14 (assay ID: Hs00978236_m1) and GUSB (the internal control; assay ID: Hs00939627_ml; Applied Biosystems) were used for gene expression analysis. 

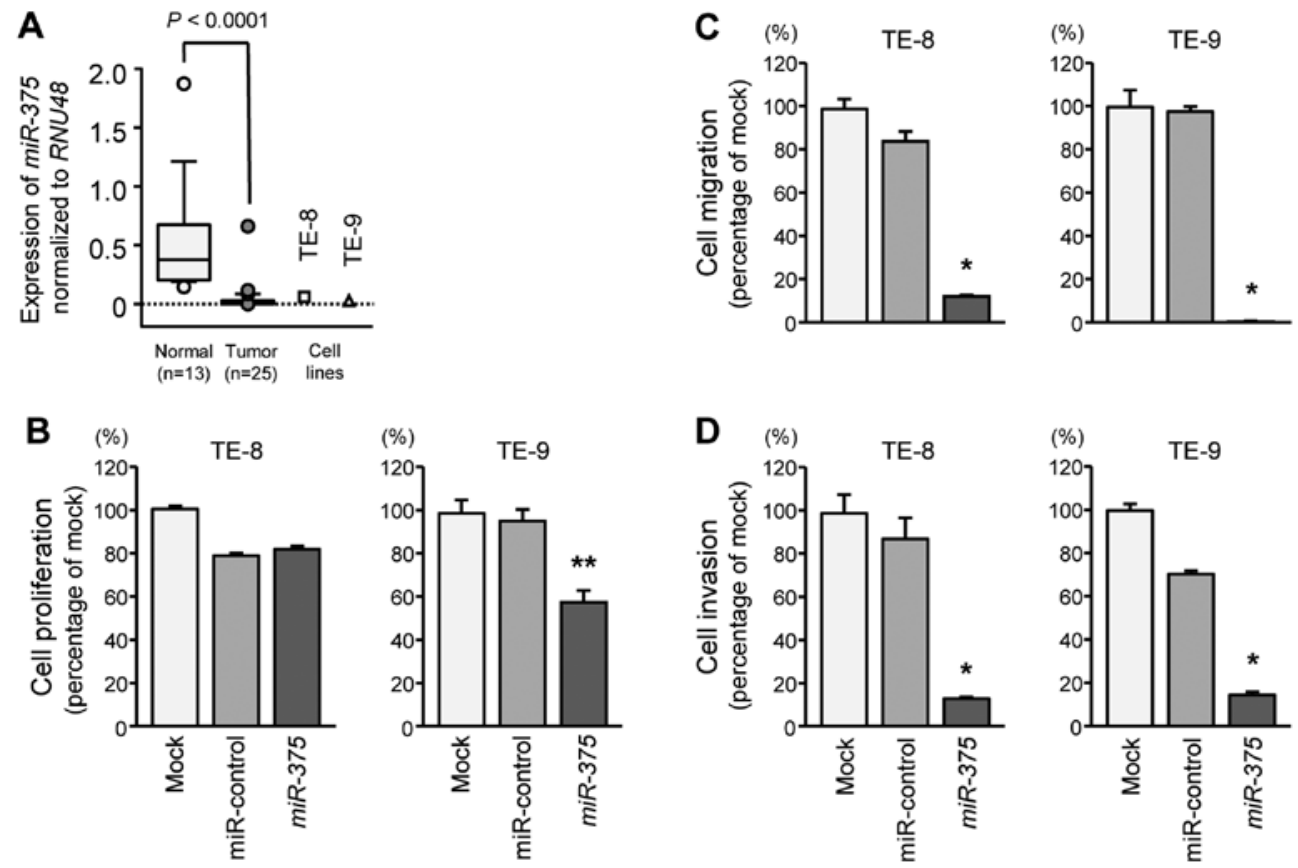

Figure 1. Expression levels of $m i R-375$ and functional assays of $m i R-375$ transfection in ESCC cell lines. (A) Expression levels of $m i R-375$ in ESCC or normal esophageal tissues and ESCC cell lines. (B) Cell proliferation was determined by XTT assays. ${ }^{*} \mathrm{P}<0.0001,{ }^{* *} \mathrm{P}<0.05$. (C) Cell migration activity was determined by migration assays. (D) Cell invasion activity was determined by Matrigel invasion assays.

Transfection with mature miRNAs and small interfering RNAs (siRNAs). The following mature miRNA was used: Ambion Pre-miR miRNA precursor for $h s a-m i R-375$ (product ID: PM10327; Applied Biosystems). The following siRNAs were used: Stealth Select RNAi siRNA, si-MMP13 (cat nos. HSS106637 and HSS106638; Invitrogen, Carlsbad, CA, USA), and negative control miRNA/siRNA (P/N: AM17111; Applied Biosystems). RNAs were incubated with Opti-MEM (Invitrogen) and Lipofectamine RNAiMax transfection reagent (Invitrogen), as previously described (13,18-20).

Cell proliferation, migration and invasion assays. TE-8 and TE-9 cells were transfected with $10 \mathrm{nM}$ miRNAs or siRNAs by reverse transfection. Cell proliferation, migration and invasion assays were performed as previously described $(13,18-20)$.

Screening of miR-375 target genes using in silico analysis and gene expression data. To identify miR-375 target genes, a combination of genome-wide gene expression and in silico analyses was conducted as previously described (13,18-20). The microarray data were deposited into the GEO repository under accession number GSE77790. Next, we selected putative miRNA target genes using microRNA.org (August, 2010 release, http://www.microrna.org) databases. Our strategy for identification of $m i R-375$ target genes is shown in Fig. 2.

Western blot analysis. Anti-human MMP-13 rabbit polyclonal IgG (1:1,000; sc30073; Santa Cruz Biotechnology, Santa Cruz, CA, USA) was used as a primary antibody. Anti-human GAPDH mouse monoclonal IgG (1:5,000; 010-25521; Wako Pure Chemical Industries, Osaka, Japan) was used as an internal loading control. The membrane was washed and incubated with a horseradish peroxidase-conjugated secondary antibody. Bands were visualized using Amersham ECL Prime Western Blotting detection reagent (GE Healthcare Life Sciences, Uppsala, Sweden).

Immunohistochemistry. Tumor samples were fixed with $10 \%$ formaldehyde in phosphate-buffered saline (PBS), embedded in paraffin and sectioned into $4-\mu \mathrm{m}$-thick slices. The sections were incubated with rabbit polyclonal anti-MMP-13 IgG (1:200; ab84594; Abcam, Cambridge, UK) at $4^{\circ} \mathrm{C}$ overnight. The procedure for immunohistochemistry was previously described (21).

Plasmid construction and Dual-luciferase reporter assays. Partial wild-type sequences of the 3 ' untranslated region (UTR) of MMP13 containing the miR-375 target site (positions 100-113 of the MMP13 3' UTR) or sequences with a deleted miR-375 target site were inserted between the XhoI and PmeI restriction sites in the 3' UTR of the hRluc gene in the psiCHECK-2 vector (product ID: C8021; Promega, Madison, WI, USA). TE-8 and TE-9 cells were transfected with $50 \mathrm{ng}$ of the vector and $10 \mathrm{nM} \mathrm{miR-375} \mathrm{using} \mathrm{Lipofectamine} 2000$ (Thermo Fisher Scientific) in Opti-MEM (Thermo Fisher Scientific). The activities of firefly and Renilla luciferases were determined in lysates of transfected cells using a Dual-luciferase reporter assay system according to the manufacturer's recommendations (product ID: E1960; Promega). Data were normalized to firefly luciferase activity (ratio of Renilla/firefly luciferase activities).

Identification of downstream genes mediated by MMP13 in ESCC cells. Gene expression analyses of si-MMP13transfected TE- 8 and TE-9 cells revealed molecular targets mediated by MMP13 in ESCC cells. This method is described in more detail in previous studies $(13,18-20)$. Microarray 
Table II. Highly expressed genes putatively regulated by $m i R-375$ in ESCC.

\begin{tabular}{|c|c|c|c|c|c|c|}
\hline \multirow{2}{*}{$\begin{array}{l}\text { Entrez } \\
\text { Gene ID }\end{array}$} & \multirow{2}{*}{$\begin{array}{l}\text { Gene } \\
\text { symbol }\end{array}$} & \multirow[b]{2}{*}{ Description } & \multirow{2}{*}{$\begin{array}{c}m i R-375 \\
\text { target } \\
\text { sites }\end{array}$} & \multicolumn{2}{|c|}{$\begin{array}{c}\text { Expression } \\
\text { in } m i R-375 \\
\text { transfectants } \\
\text { FC }\left(\log _{2}\right)\end{array}$} & \multirow{2}{*}{$\begin{array}{c}\text { GEO data } \\
(\mathrm{GSE} 20347) \\
\text { FC }\left(\log _{2}\right)\end{array}$} \\
\hline & & & & TE-8 & TE-9 & \\
\hline 4322 & $M M P 13$ & Matrix metalloproteinase 13 & 1 & -2.24 & -1.76 & 5.12 \\
\hline 6004 & $R G S 16$ & Regulator of G-protein signaling 16 & 3 & -1.50 & -0.92 & 2.45 \\
\hline 4920 & ROR2 & Receptor tyrosine kinase-like orphan receptor 2 & 1 & -0.80 & -0.59 & 2.14 \\
\hline 10202 & DHRS2 & Dehydrogenase/reductase (SDR family) member 2 & 3 & -3.07 & -0.83 & 2.02 \\
\hline 1956 & $E G F R$ & Epidermal growth factor receptor & 1 & -0.93 & -0.78 & 1.58 \\
\hline 655 & $B M P 7$ & Bone morphogenetic protein 7 & 1 & -0.85 & -0.74 & 1.54 \\
\hline 23363 & OBSL1 & Obscurin-like 1 & 1 & -0.80 & -0.71 & 1.52 \\
\hline 23035 & PHLPP2 & PH domain and leucine rich repeat protein phosphatase 2 & 1 & -0.69 & -0.64 & 1.15 \\
\hline 1896 & $E D A$ & Ectodysplasin A & 1 & -0.72 & -0.63 & 1.09 \\
\hline
\end{tabular}

results were deposited in the GEO database (accession number GSE82108).

Statistical analysis. Relationships between two or three variables and numerical values were analyzed using the MannWhitney U test or the Bonferroni-adjusted Mann-Whitney test. Spearman's rank test was used to evaluate the correlations between the expression levels of $m i R-375$ and MMP13. Expert StatView version 5.0 (SAS Institute, Inc., Cary, NC, USA) was used in these analyses.

\section{Results}

Expression levels of miR-375 in ESCC clinical specimens and cell lines. We evaluated the expression levels of $m i R-375$ in ESCC tissues $(n=25)$, normal esophageal specimens $(n=13)$, and ESCC cell lines (TE-8 and TE-9). The patient backgrounds and clinicopathological characteristics are shown in Table I. The expression levels of $m i R-375$ were significantly downregulated in cancer tissues and ESCC cell lines compared with those in normal tissues $(\mathrm{P}<0.0001$; Fig. 1A). Additionally, there were no significant relationships between the expression level of $m i R-375$ and any of the clinicopathological parameters examined in this study (recurrence, $\mathrm{T}$ stage, $\mathrm{N}$ stage, vascular invasion, or survival rate).

Effects of miR-375 restoration on cell proliferation, migration and invasion in ESCC cell lines. To investigate the antitumor functions of $m i R-375$, we performed gain-of-function studies using mature miRNA transfection of TE- 8 and TE-9 cells.

Cell proliferation was significantly suppressed by $m i R-375$ transfection in TE-9 cells in comparison with that of mock or miR-control transfectants (Fig. 1B). However, no changes were detected in TE-8 cells (Fig. 1B).

Migration assays showed that cell migration activity was significantly inhibited by $m i R-375$ transfection in TE- 8 and TE-9 cells in comparison with that in mock or miR-control transfectants (Fig. 1C). Additionally, Matrigel invasion assays

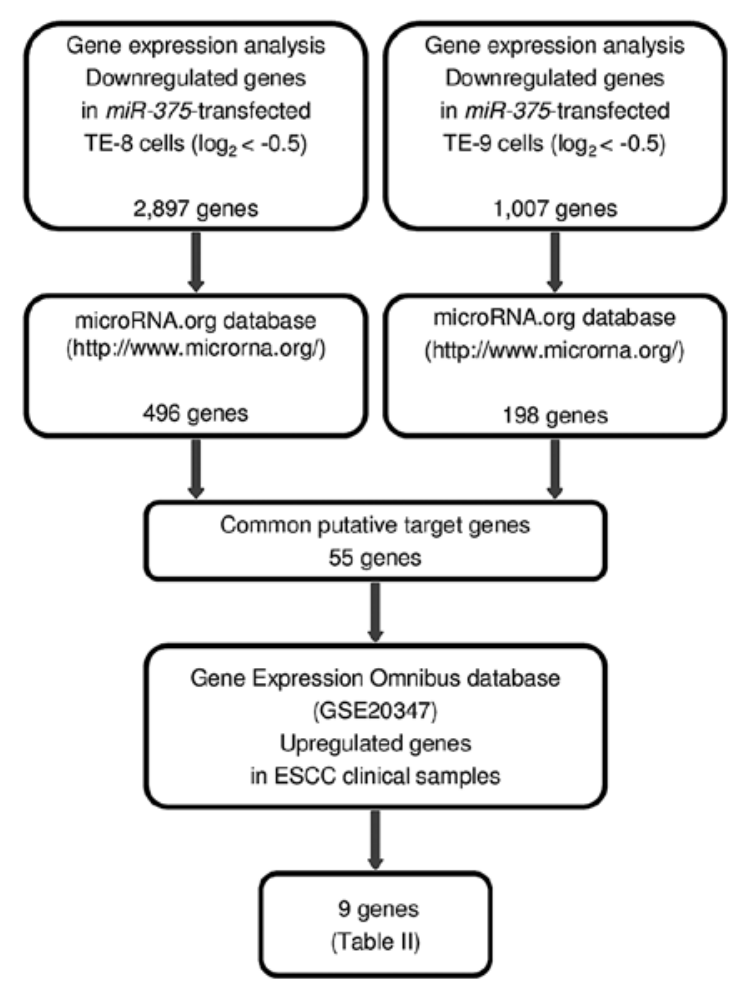

Figure 2. The strategy for analysis of $m i R-375$ target genes.

demonstrated that cell invasion activity was significantly inhibited by $m i R-375$ transfection in TE- 8 and TE-9 cells in comparison with that in mock or miR-control transfectants (Fig. 1D).

Identification of putative target genes regulated by $\mathrm{miR}-375$ in ESCC cells. To gain additional insights into the molecular pathways regulated by antitumor $m i R-375$ in ESCC cells, we used a combination of in silico and gene expression analyses. The strategy for identification of the miR-375-regulated genes in ESCC cells is shown in Fig. 2. 
A

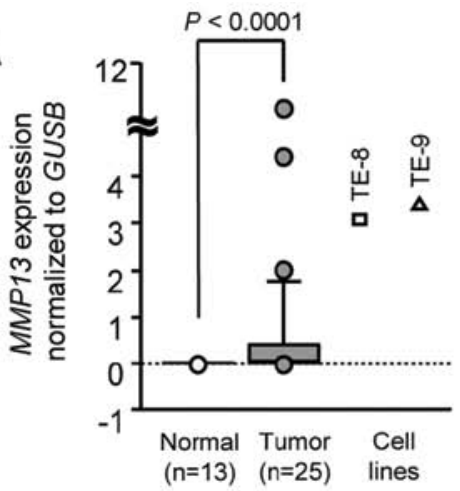

C
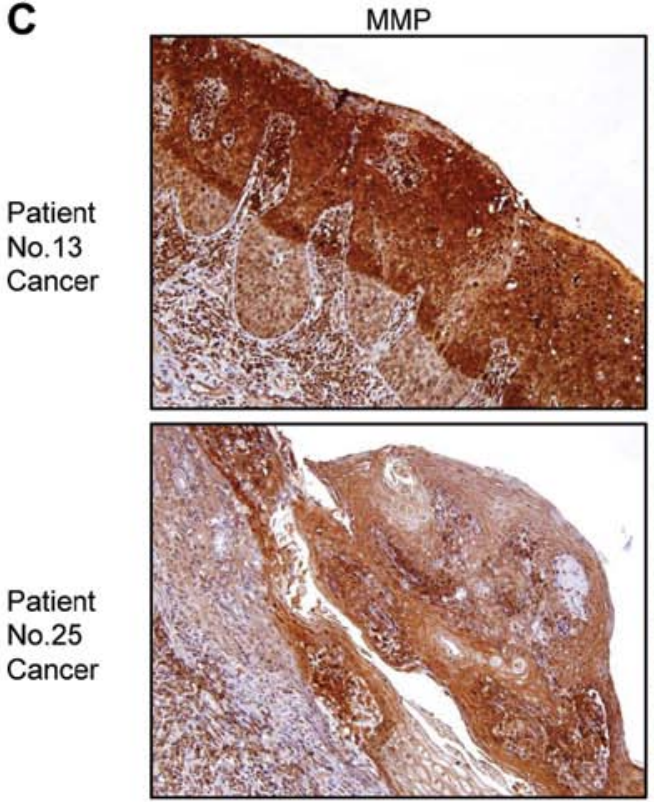

Patient

No. 25

Cancer

Patient

Cancer

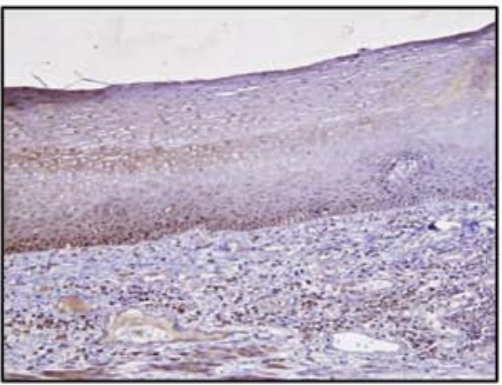

B

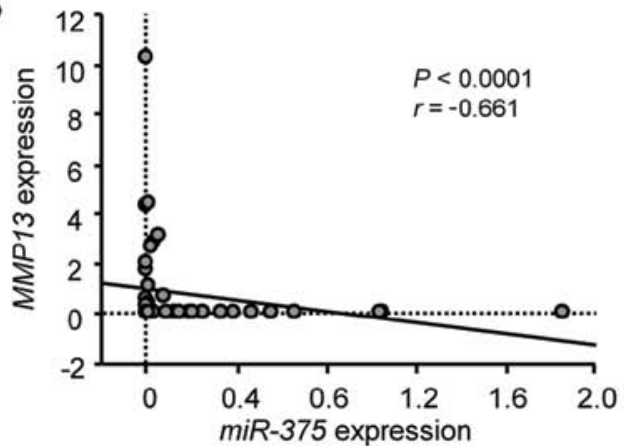

HE
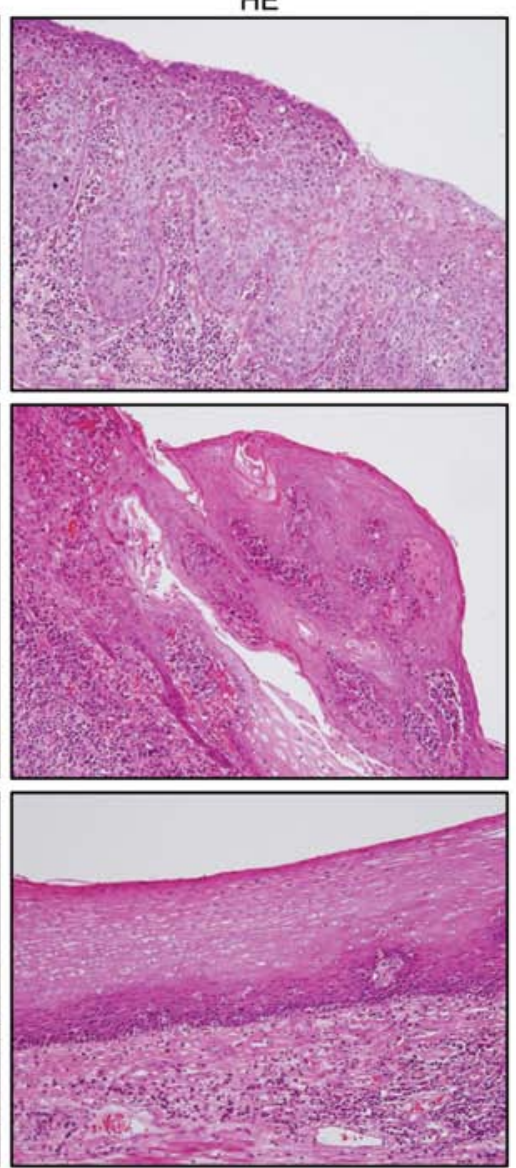

Figure 3. Expression levels of MMP13 mRNA and immunohistochemical staining of MMP13 protein in ESCC specimens. (A) Expression levels of $M M P 13$ mRNA in ESCC or normal esophageal tissues and ESCC cell lines. (B) The expression of $m i R-375$ and $M M P 13$ mRNA was negatively correlated (r=-0.661 and $\mathrm{P}<0.0001)$. (C) Immunohistochemical staining of MMP13 in ESCC specimens. All ESCC tissues were stained positively, whereas normal esophageal tissues were stained negatively or weakly (left panel, MMP13 staining; right panel, hematoxylin-eosin staining; original magnification, $\mathrm{x} 200$ ).

In gene expression analyses, 2,897 and 1,007 genes were downregulated $\left(\log _{2}\right.$ ratio <-0.5) in TE-8 and TE-9 $m i R-375$ transfectants, respectively, in comparison with that in control transfectants. Our present expression data were deposited in the Gene Expression Omnibus (GEO accession number GSE77790). Among these downregulated genes, we searched for genes having putative miR-375 binding sites in their 3 UTRs using the microRNA.org database. A total of 55 genes were identified as putative target genes of $m i R-375$, and nine genes were upregulated in ESCC clinical specimens, as determined using ESCC expression data (GEO accession number: GSE20347; Table II).
In this study, we focused on $M M P 13$ because its expression was most upregulated in ESCC clinical specimens and most downregulated in $m i R-375$ transfectants. Moreover, previous studies have shown that the activation of MMPs is associated with cancer cell aggressiveness (22).

Expression of MMP13 in ESCC clinical specimens. Next, we validated the upregulation of MMP13 in the ESCC clinical specimens at both the mRNA and the protein levels. The expression of MMP13 was significantly upregulated in 25 ESCC specimens and ESCC cell lines compared with that in 13 normal specimens $(\mathrm{P}<0.0001$; Fig. $3 \mathrm{~A})$. The 
A

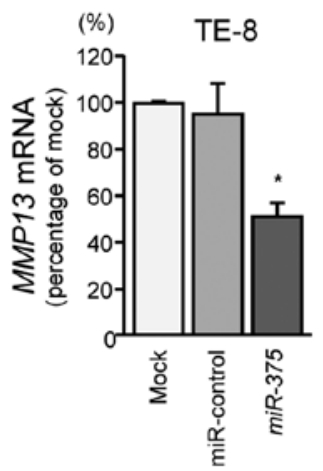

B

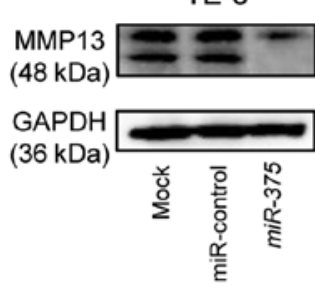

Positions 100-113 of MMP13 3' UTR
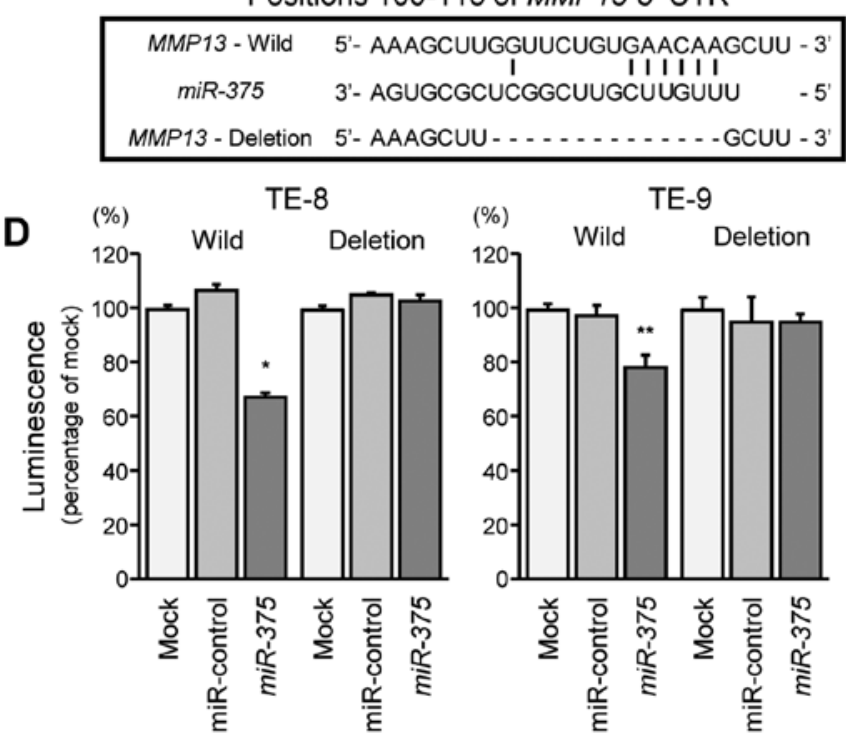

Figure 4. Direct regulation of $M M P 13$ by $m i R-375$ in ESCC cell lines (A) Expression levels of $M M P 13$ mRNA $72 \mathrm{~h}$ after transfection with $m i R-375$. (B) $M M P 13$ protein expression $72 \mathrm{~h}$ after transfection with $m i R-375$. (C) Putative miR-375 binding sites in the 3' UTR of MMP13 mRNA. (D Luciferase reporter assay using vectors encoding putative $m i R-375$ target sites at positions 100-113 for both wild-type and deletion-type constructs. Renilla luciferase values were normalized to firefly luciferase values. ${ }^{*} \mathrm{P}<0.0001,{ }^{* *} \mathrm{P}<0.05$

Spearman's rank tests showed negative correlations between the expression of $m i R-375$ and that of $M M P 13$ ( $\mathrm{r}=-0.661$, $\mathrm{P}<0.0001$; Fig. 3B).

Immunohistochemistry showed that MMP13 tended to be strongly expressed in ESCC lesions, whereas low expression was observed in normal esophageal epithelium (Fig. 3C).

Direct regulation of MMP13 by miR-375 in ESCC cells. We performed qRT-PCR to validate $m i R$-375-mediated repression of MMP13 expression in ESCC cell lines. Our results showed that MMP13 mRNA was significantly reduced in $m i R-375$
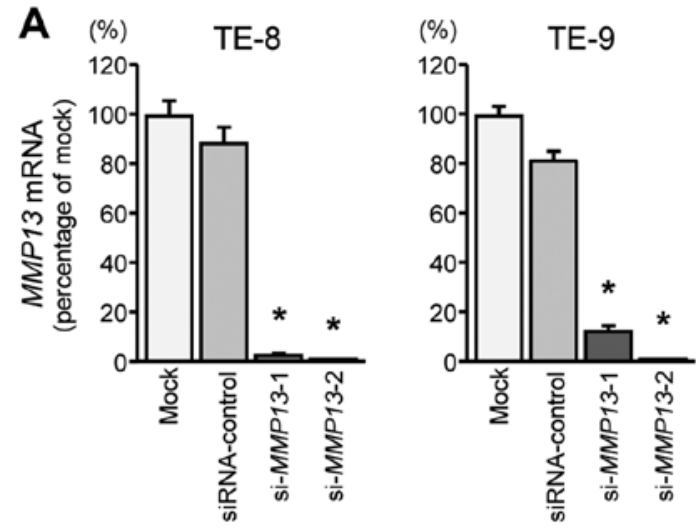

B

TE-8

TE-9
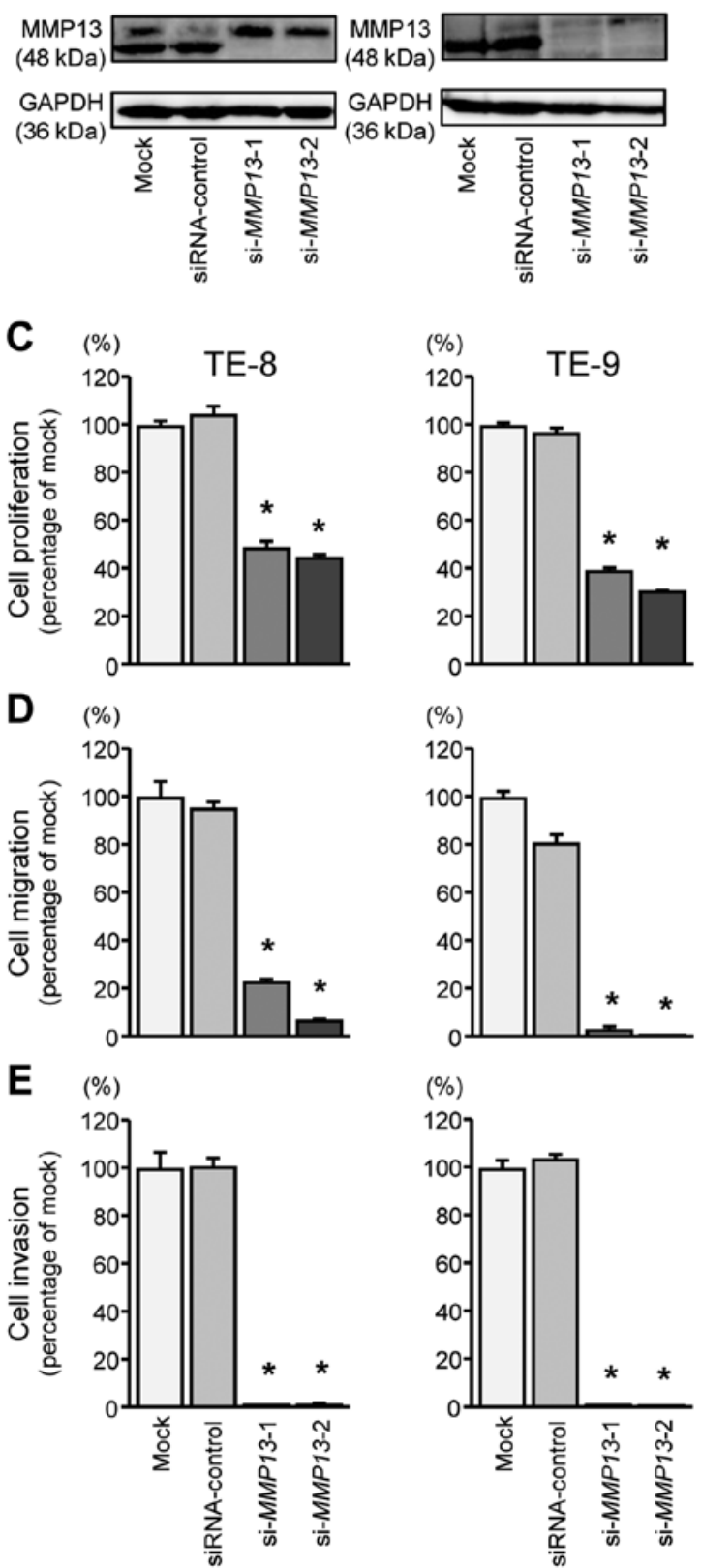

Figure 5. Loss of function studies using siRNAs. (A) Expression levels of $M M P 13$ mRNA after transfection with $s i-M M P 13$ in ESCC cell lines. (B) $M M P 13$ protein expression $72 \mathrm{~h}$ after transfection with si-MMP13. (C) Cell proliferation was determined by XTT assays. Inhibition of cell proliferation was observed in si-MMP13-transfected cell lines. (D) Cell migration activity was determined by migration assays. (E) Cell invasion was determined by Matrigel invasion assays. Inhibition of migration and invasion was observed in si-MMP13-transfected cell lines. " $\mathrm{P}<0.0001$. 


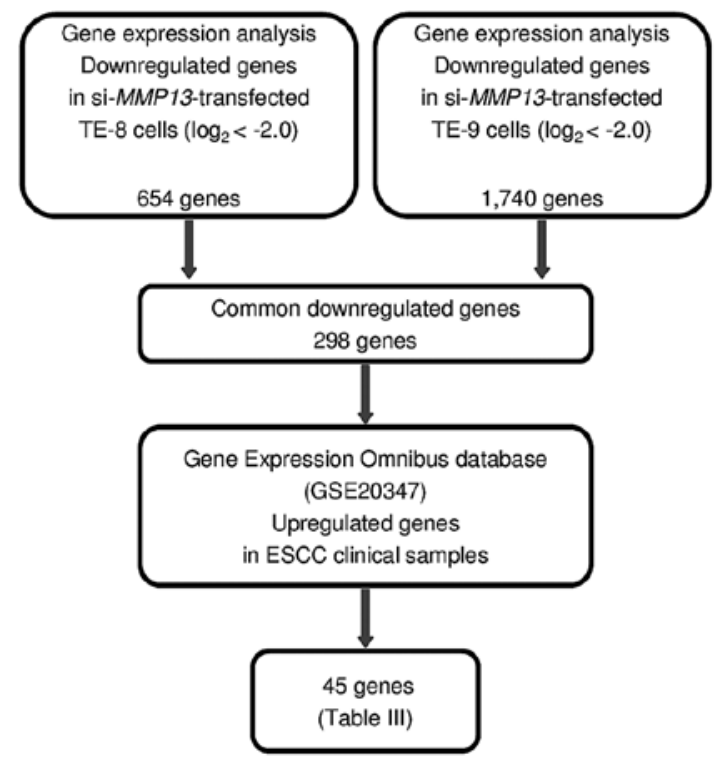

Figure 6. The strategy for analysis of MMP13 downstream genes.

transfectants in comparison with that in mock or miR-control transfectants $(\mathrm{P}<0.0001$; Fig. 4A). MMP13 protein expression was also repressed in miR-375 transfectants (Fig. 4B).

Next, we performed luciferase reporter assays using TE-8 and TE-9 cells to determine whether MMP13 had an actual target site for miR-375 binding. The microRNA.org database predicted that there was one putative target site in the $3^{\prime}$ UTR of MMP13 (Fig. 4C). Compared with the miR-control, luminescence intensity was significantly reduced by transfection with $m i R-375$ at the $m i R-375$ target site, positions $100-113$, in the 3 ' UTR of MMP13 (Fig. 4D).

Effects of silencing MMP13 on proliferation, migration and invasion in ESCC cells. To investigate the functional roles of MMP13 in ESCC cell lines, we performed loss-of-function assays by transfection of $s i-M M P 13$ into TE- 8 and TE-9 cells.

First, we evaluated the knockdown efficiency of $s i-M M P 13$ transfection in ESCC cell lines. In the present study, we used two siRNAs targeting MMP13 (si-MMP13-1 and si-MMP13-2). According to qRT-PCR and western blot analyses, both siRNAs effectively downregulated MMP13 expression in both cell lines (Fig. 5A and B).

Cell proliferation, migration and invasion assays demonstrated that cell proliferation, migration, and invasion were inhibited in si-MMP13-transfected cells compared with those in mock- or siRNA-control-transfected cells (Fig. 5C-E).

Identification of downstream genes regulated by MMP13 in ESCC cells. To determine which downstream genes were regulated by MMP13, genome-wide gene expression and in silico analyses were performed in TE-8 and TE-9 cells transfected with $s i-M M P 13$.

Our expression analysis showed that a total of 298 genes were commonly downregulated $\left(\log _{2}\right.$ ratio <-2.0) in TE-8 and TE-9 cells following si-MMP13 transfection. Among these genes, 52 were upregulated in ESCC clinical specimens, as determined using ESCC expression data (GEO accession number: GSE20347; Fig. 6 and Table III).
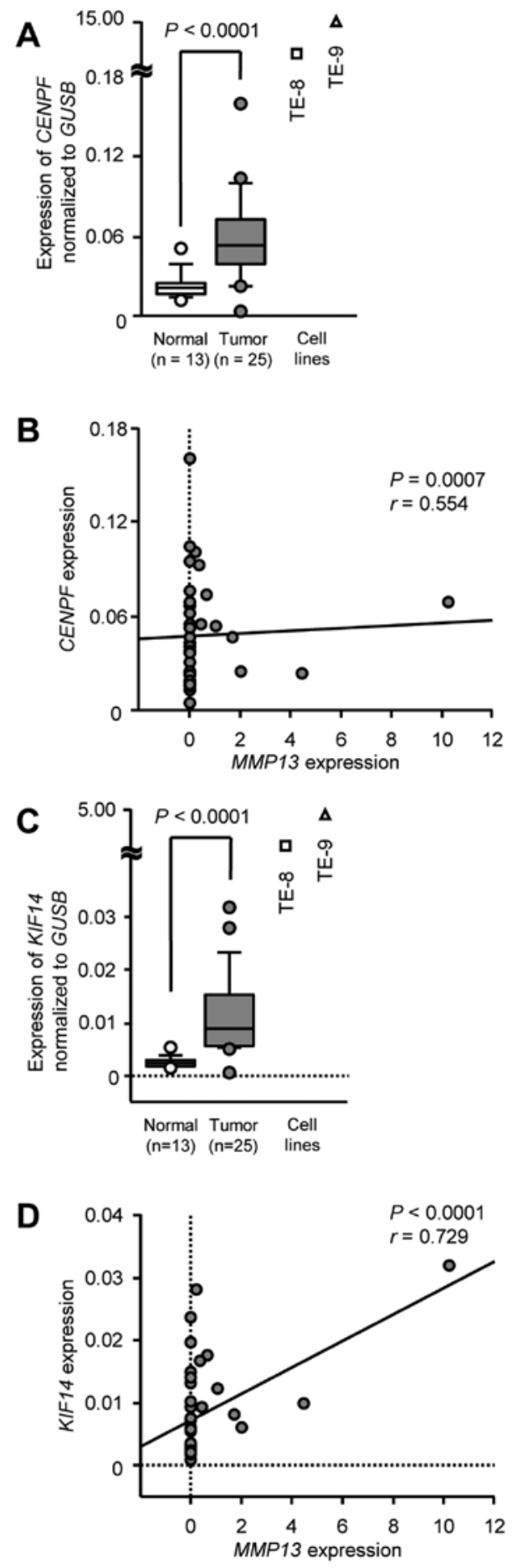

Figure 7. mRNA expression levels of $M M P 13$ downstream genes (CENPF and $K I F 14$ ) in ESCC specimens. (A and C) Expression levels of $C E N P F$ and KIF14 mRNA in ESCC or normal esophageal tissues and ESCC cell lines. (B and D) The expression levels of MMP13/CENPF and MMP13/KIF14 mRNAs were positively correlated $(\mathrm{P}<0.0001)$.

We then validated the upregulation of CENPF and KIF14 mRNAs in ESCC clinical specimens. The expression of $C E N P F$ and KIF14 mRNAs was significantly upregulated in 25 ESCC specimens and ESCC cell lines compared with that in 13 normal specimens $(\mathrm{P}<0.0001$; Fig. 7A and $\mathrm{C})$. The Spearman's rank tests showed correlations between the expression of MMP13 and that of CENPF or KIF14 (CENPF: $\mathrm{r}=0.554$, $\mathrm{P}=0.0007$, Fig. 7B; KIF14: $\mathrm{r}=0.729, \mathrm{P}<0.0001$, Fig. 7D). 
Table III. Downregulated genes in si-MMP13-transfected ESCC cell lines.

\begin{tabular}{|c|c|c|c|c|c|}
\hline \multirow{2}{*}{$\begin{array}{l}\text { Entrez } \\
\text { gene ID }\end{array}$} & \multirow[b]{2}{*}{ Gene symbol } & \multirow[b]{2}{*}{ Description } & \multicolumn{2}{|c|}{$\begin{array}{l}\text { Expression } \\
\text { in si-MMP13 } \\
\text { transfectants } \\
\text { FC }\left(\log _{2}\right)\end{array}$} & \multirow{2}{*}{$\begin{array}{c}\text { GEO data } \\
(\text { GSE20347) } \\
\text { FC }\left(\log _{2}\right)\end{array}$} \\
\hline & & & TE8 & TE9 & \\
\hline 4322 & $M M P 13$ & Matrix metallopeptidase 13 (collagenase 3 ) & -4.42 & -4.47 & 5.12 \\
\hline 1063 & $C E N P F$ & Centromere protein F, 350/400 kDa & -2.96 & -5.18 & 2.31 \\
\hline 9928 & KIF 14 & Kinesin family member 14 & -2.28 & -4.66 & 2.14 \\
\hline 2842 & GPR19 & G protein-coupled receptor 19 & -2.67 & -3.74 & 2.12 \\
\hline 983 & $C D K 1$ & Cyclin-dependent kinase 1 & -2.07 & -3.78 & 1.95 \\
\hline 55165 & CEP55 & Centrosomal protein $55 \mathrm{kDa}$ & -3.33 & -4.79 & 1.94 \\
\hline 1033 & $C D K N 3$ & Cyclin-dependent kinase inhibitor 3 & -2.08 & -3.73 & 1.94 \\
\hline 7153 & TOP $2 A$ & Topoisomerase (DNA) II alpha 170 kDa & -3.36 & -5.01 & 1.91 \\
\hline 10403 & NDC80 & NDC80 kinetochore complex component & -2.19 & -3.69 & 1.76 \\
\hline 9787 & $D L G A P 5$ & Discs, large (Drosophila) homolog-associated protein 5 & -2.27 & -3.32 & 1.72 \\
\hline 55215 & FANCI & Fanconi anemia, complementation group I & -2.27 & -3.97 & 1.70 \\
\hline 23306 & TMEM194A & Transmembrane protein 194A & -2.31 & -2.79 & 1.68 \\
\hline 4751 & $N E K 2$ & NIMA-related kinase 2 & -2.70 & -3.84 & 1.66 \\
\hline 2735 & GLII & GLI family zinc finger 1 & -2.70 & -3.31 & 1.63 \\
\hline 3161 & $H M M R$ & Hyaluronan-mediated motility receptor (RHAMM) & -4.06 & -5.29 & 1.60 \\
\hline 259266 & $A S P M$ & $\begin{array}{l}\text { Asp (abnormal spindle) homolog, microcephaly } \\
\text { associated (Drosophila) }\end{array}$ & -2.17 & -3.81 & 1.56 \\
\hline 4998 & ORCl & Origin recognition complex, subunit 1 & -2.23 & -3.08 & 1.53 \\
\hline 57405 & $S P C 25$ & SPC25, NDC80 kinetochore complex component & -2.16 & -4.12 & 1.48 \\
\hline 28951 & TRIB2 & Tribbles pseudokinase 2 & -2.28 & -2.35 & 1.44 \\
\hline 9603 & NFE2L3 & Nuclear factor, erythroid 2-like 3 & -2.00 & -2.51 & 1.42 \\
\hline 9638 & FEZ1 & Fasciculation and elongation protein zeta 1 (zygin I) & -2.27 & -2.97 & 1.42 \\
\hline 9918 & NCAPD2 & Non-SMC condensin I complex, subunit D2 & -2.12 & -2.79 & 1.38 \\
\hline 7468 & WHSCl & Wolf-Hirschhorn syndrome candidate 1 & -2.43 & -3.36 & 1.33 \\
\hline 100288413 & ERVMER34-1 & Endogenous retrovirus group MER34, member 1 & -2.76 & -3.78 & 1.32 \\
\hline 1062 & CENPE & Centromere protein E, $312 \mathrm{kDa}$ & -2.60 & -3.91 & 1.29 \\
\hline 55063 & $Z C W P W 1$ & Zinc finger, CW type with PWWP domain 1 & -3.19 & -3.44 & 1.25 \\
\hline 81624 & DIAPH3 & Diaphanous-related formin 3 & -2.22 & -3.54 & 1.25 \\
\hline 6119 & $R P A 3$ & Replication protein $\mathrm{A} 3,14 \mathrm{kDa}$ & -2.34 & -3.42 & 1.24 \\
\hline 8318 & $C D C 45$ & Cell division cycle 45 & -2.13 & -4.07 & 1.23 \\
\hline 64151 & $N C A P G$ & Non-SMC condensin I complex, subunit G & -3.25 & -3.92 & 1.22 \\
\hline 7083 & $T K 1$ & Thymidine kinase 1 , soluble & -2.11 & -3.86 & 1.22 \\
\hline 55732 & Clorf112 & Chromosome 1 open reading frame 112 & -2.06 & -2.62 & 1.22 \\
\hline 1058 & CENPA & Centromere protein A & -2.02 & -3.86 & 1.18 \\
\hline 55635 & $D E P D C 1$ & DEP domain containing 1 & -2.33 & -3.44 & 1.18 \\
\hline 3925 & STMN1 & Stathmin 1 & -2.66 & -4.51 & 1.17 \\
\hline 3092 & $H I P 1$ & Huntingtin interacting protein 1 & -2.71 & -3.51 & 1.17 \\
\hline 5427 & POLE2 & Polymerase (DNA directed), epsilon 2, accessory subunit & -2.18 & -4.37 & 1.15 \\
\hline 1719 & DHFR & Dihydrofolate reductase & -2.46 & -3.63 & 1.14 \\
\hline 54830 & NUP62CL & Nucleoporin 62 kDa C-terminal like & -2.17 & -2.22 & 1.10 \\
\hline 5062 & $P A K 2$ & p21 protein $(\mathrm{Cdc} 42 / \mathrm{Rac})$-activated kinase 2 & -2.37 & -2.60 & 1.09 \\
\hline 100129361 & LOC100129361 & Chromosome $\mathrm{X}$ open reading frame 69 -like & -2.57 & -2.46 & 1.09 \\
\hline 5933 & $R B L 1$ & Retinoblastoma-like 1 & -3.24 & -4.43 & 1.08 \\
\hline 4288 & MKI67 & Marker of proliferation Ki-67 & -2.14 & -4.87 & 1.03 \\
\hline 81691 & LOC81691 & Exonuclease NEF-sp & -2.62 & -3.61 & 1.03 \\
\hline 675 & $B R C A 2$ & Breast cancer 2 , early onset & -2.90 & -4.04 & 1.00 \\
\hline
\end{tabular}




\section{Discussion}

Numerous studies of miRNA expression signatures in ESCC have shown that $m i R-375$ is frequently downregulated in cancer tissues and functions as an antitumor miRNA $(14,23)$. In the present study, we confirmed that $m i R$ - 375 was markedly downregulated in cancer tissues and that ectopic expression of $m i R-375$ significantly suppressed cancer cell migration and invasion. Thus, we found that loss of $m i R-375$ expression enhanced cancer cell aggressiveness in ESCC. Many previous studies have shown that the expression of $m i R$-375 is markedly decreased in several types of cancers and that $m i R-375$ functions as an antitumor miRNA $(15,24)$. In contrast to these antitumor activities, $m i R-375$ is upregulated in pediatric acute myeloid leukemia (AML) and prostate cancer, suggesting that $m i R-375$ acts as an oncogenic miRNA in these diseases $(25,26)$. The dual function of $m i R-375$ is very unique; thus, it is important to identify $m i R-375$-regulated pathways in various cancer types.

It is also important to elucidate novel RNA networks regulated by antitumor $m i R-375$ in ESCC cells. Previous studies have shown that insulin-like growth factor 1 receptor $(I G F I R)$, lactate dehydrogenase B $(L D H B)$, and astrocyte elevated gene-1/metadherin (AEG-1/MTDH) are directly regulated by $m i R-375$ in ESCC cells $(16,17)$. These target genes are upregulated in ESCC clinical specimens and functioned as oncogenes in this disease. Another unique characteristic of miRNAs is that a single miRNA can regulate a large number of RNA transcripts in human cells $(27,28)$. Thus, the continuous identification of $m i R$-375-regulated oncogenes in ESCC cells is important for elucidation of the molecular pathogenesis of ESCC.

In this study, we identified $M M P 13$ as a direct target of antitumor $m i R$ - 375 in ESCC cells. MMP13 (also known as collagenase 3 ) is a member of the collagenase subfamily of MMPs and functions to degrade a wide range of extracellular matrix components, including tenascin $\mathrm{C}$, fibronectin and type I-IV collagen (29). Thus, MMP13 has a wide range of proteolytic functions, suggesting that MMP13 is involved in several physiological and pathological processes (30). High expression of MMP13 has been reported in rheumatoid arthritis, osteoarthritis and several types of cancers (22). Previous studies have also shown that high expression of MMP13 is associated with vascular invasion and lymph node metastasis in ESCC (31). Our present data demonstrated that knockdown of MMP13 markedly reduced cancer cell migration and invasion in ESCC cells.

The MMP13 gene has also been reported to be epigenetically regulated by several other miRNAs, including $m i R-125 b$ and $m i R-143$, in cancer cells (32-34). Notably, our miRNA signatures have shown that $m i R-125 b$ and $m i R-143$ are downregulated in ESCC and in oral and hypopharyngeal squamous cell carcinoma (12-14). Moreover, functional assays have indicated that these miRNAs act as tumor suppressors in several cancers, including ESCC cells (32-35). Loss of the expression of several antitumor miRNAs and activation of MMP13 may enhance cancer cell aggressiveness and metastasis. Thus, identification of $m i R-375 / M M P 13$-mediated cancer pathways may facilitate the discovery of candidate therapeutic targets in ESCC.
Based on the above, we further investigated the downstream genes mediated by MMP13 in ESCC cells using genome-wide gene expression analysis. Our data showed that several centromere-associated proteins were regulated by MMP13-mediated genes, such as CENPF, CENPE, CENPA, CEP55, NDC80 and $S P C 25$. Moreover, cell cycle-promoting genes, e.g., KIF14, $C D K 1, T O P 2 A, C D C 45$ and PAK2, were also downregulated by $s i-M M P 13$ in this study. Recent studies have reported that several genes encoding mitotic apparatus components are upregulated in cancer cells and contribute to cancer cell phenotypes $(36,37)$. Therefore, overexpression of genes encoding mitotic apparatus components may represent a potential target for cancer drug development (38). Several compounds that inhibit centromere proteins and mitotic kinesins are being tested as potential cancer therapies in clinical trials (39).

Among these genes, we validated the overexpression of CENPF and KIF14 in ESCC clinical specimens. Previous studies have shown that $C E N P F$ is a master regulator of prostate cancer malignancy and that high expression of $C E P N F$ is a prognostic indicator of poor survival and metastasis in patients with ESCC (40). KIF14 is a member of the kinesin superfamily of proteins and functions as a microtubule motor protein involved in cytokinesis and chromosome segregation (41). Overexpression of KIFI4 has been reported in several cancers, and its expression is associated with cancer cell phenotypes $(42,43)$. An in-depth functional analysis of these genes in ESCC cells is necessary to further characterize these pathways. Identification of the downstream genes regulated by the miR-375/MMP13 axis may lead to a better understanding of ESCC aggressiveness.

In conclusion, downregulation of $m i R-375$ was frequently observed in ESCC clinical specimens, and $m i R-375$ was shown to function as an antitumor miRNA in ESCC cells. To the best of our knowledge, this is the first report demonstrating that $M M P 13$ is directly regulated by antitumor $m i R-375$ and acts to regulate several cell cycle promoting genes. The identification of novel molecular pathways and targets regulated by the $m i R-375 / M M P 13$ axis may lead to a better understanding of ESCC molecular pathogenesis.

\section{Acknowledgements}

We wish to thank the Joint Research Laboratory, Kagoshima University Graduate School of Medical and Dental Sciences, for the use of their facilities. The present study was supported by KAKENHI (C) grant 15K10801.

\section{References}

1. Hongo M, Nagasaki Y and Shoji T: Epidemiology of esophageal cancer: Orient to Occident. Effects of chronology, geography and ethnicity. J Gastroenterol Hepatol 24: 729-735, 2009.

2. Pennathur A, Gibson MK, Jobe BA and Luketich JD: Oesophageal carcinoma. Lancet 381: 400-412, 2013.

3. Ohashi S, Miyamoto S, Kikuchi O, Goto T, Amanuma Y and Muto M: Recent advances from basic and clinical studies of esophageal squamous cell carcinoma. Gastroenterology 149: 1700-1715, 2015.

4. Enzinger PC and Mayer RJ: Esophageal cancer. N Engl J Med 349: 2241-2252, 2003.

5. Lu J, Getz G, Miska EA, Alvarez-Saavedra E, Lamb J, Peck D, Sweet-Cordero A, Ebert BL, Mak RH, Ferrando AA, et al: MicroRNA expression profiles classify human cancers. Nature 435: 834-838, 2005. 
6. Calin GA and Croce CM: MicroRNA signatures in human cancers. Nat Rev Cancer 6: 857-866, 2006.

7. Bartel DP: MicroRNAs: Genomics, biogenesis, mechanism, and function. Cell 116: 281-297, 2004.

8. Harada K, Baba Y, Ishimoto T, Shigaki H, Kosumi K, Yoshida N, Watanabe $\mathrm{M}$ and $\mathrm{Baba} \mathrm{H}$ : The role of microRNA in esophageal squamous cell carcinoma. J Gastroenterol 51: 520-530, 2016.

9. Kikkawa N, Hanazawa T, Fujimura L, Nohata N, Suzuki H, Chazono H, Sakurai D, Horiguchi S, Okamoto Y and Seki N: miR-489 is a tumour-suppressive miRNA target PTPN11 in hypopharyngeal squamous cell carcinoma (HSCC). Br J Cancer 103: 877-884, 2010.

10. Nohata N, Hanazawa T, Kikkawa N, Sakurai D, Fujimura L, Chiyomaru T, Kawakami K, Yoshino H, Enokida H, Nakagawa M, et al: Tumour suppressive microRNA-874 regulates novel cancer networks in maxillary sinus squamous cell carcinoma. $\mathrm{Br} J$ Cancer 105: 833-841, 2011.

11. Nohata N, Hanazawa T, Kinoshita T, Inamine A, Kikkawa N, Itesako T, Yoshino H, Enokida H, Nakagawa M, Okamoto Y, et al: Tumour-suppressive microRNA-874 contributes to cell proliferation through targeting of histone deacetylase 1 in head and neck squamous cell carcinoma. Br J Cancer 108: 1648-1658, 2013.

12. Fukumoto I, Kinoshita T, Hanazawa T, Kikkawa N, Chiyomaru T, Enokida H, Yamamoto N, Goto Y, Nishikawa R, Nakagawa M, et al: Identification of tumour suppressive microRNA-451a in hypopharyngeal squamous cell carcinoma based on microRNA expression signature. Br J Cancer 111: 386-394, 2014.

13. Fukumoto I, Hanazawa T, Kinoshita T, Kikkawa N, Koshizuka K, Goto Y, Nishikawa R, Chiyomaru T, Enokida H, Nakagawa M, et al: MicroRNA expression signature of oral squamous cell carcinoma: Functional role of microRNA-26a/b in the modulation of novel cancer pathways. Br J Cancer 112: 891-900, 2015.

14. Kano M, Seki N, Kikkawa N, Fujimura L, Hoshino I, Akutsu Y, Chiyomaru T, Enokida H, Nakagawa $M$ and Matsubara $\mathrm{H}$ : miR-145, miR-133a and miR-133b: Tumor-suppressive miRNAs target FSCN1 in esophageal squamous cell carcinoma. Int J Cancer 127: 2804-2814, 2010.

15. Kinoshita T, Hanazawa T, Nohata N, Okamoto Y and Seki N: The functional significance of microRNA-375 in human squamous cell carcinoma: Aberrant expression and effects on cancer pathways. J Hum Genet 57: 556-563, 2012.

16. Isozaki Y, Hoshino I, Nohata N, Kinoshita T, Akutsu Y, Hanari N, Mori M, Yoneyama Y, Akanuma N, Takeshita N, et al: Identification of novel molecular targets regulated by tumor suppressive miR-375 induced by histone acetylation in esophageal squamous cell carcinoma. Int J Oncol 41: 985-994, 2012

17. Kong KL, Kwong DL, Chan TH, Law SY, Chen L, Li Y, Qin YR and Guan XY: MicroRNA-375 inhibits tumour growth and metastasis in oesophageal squamous cell carcinoma through repressing insulin-like growth factor 1 receptor. Gut 61: 33-42, 2012.

18. Matsushita R, Yoshino H, Enokida H, Goto Y, Miyamoto K, Yonemori $\mathrm{M}$, Inoguchi $\mathrm{S}$, Nakagawa $\mathrm{M}$ and Seki N: Regulation of UHRF1 by dual-strand tumor-suppressor microRNA-145 (miR-145-5p and miR-145-3p): Inhibition of bladder cancer cell aggressiveness. Oncotarget 7: 28460-28487, 2016.

19. Goto Y, Kojima S, Nishikawa R, Kurozumi A, Kato M, Enokida H, Matsushita R, Yamazaki K, Ishida Y, Nakagawa M, et al: MicroRNA expression signature of castration-resistant prostate cancer: The microRNA-221/222 cluster functions as a tumour suppressor and disease progression marker. Br J Cancer 113: 1055-1065, 2015

20. Goto Y, Kojima S, Nishikawa R, Enokida H, Chiyomaru T, Kinoshita T, Nakagawa M, Naya Y, Ichikawa T and Seki N The microRNA-23b/27b/24-1 cluster is a disease progression marker and tumor suppressor in prostate cancer. Oncotarget 5: 7748-7759, 2014

21. Kita Y, Nishizono Y, Okumura H, Uchikado Y, Sasaki K, Matsumoto M, Setoyama T, Tanoue K, Omoto I, Mori S, et al Clinical and biological impact of cyclin-dependent kinase subunit 2 in esophageal squamous cell carcinoma. Oncol Rep 31: 1986-1992, 2014

22. Brinckerhoff CE, Rutter JL and Benbow U: Interstitial collagenases as markers of tumor progression. Clin Cancer Res 6: 4823-4830, 2000.

23. Yan JW, Lin JS and He XX: The emerging role of miR-375 in cancer. Int J Cancer 135: 1011-1018, 2014
24. Hui AB, Bruce JP, Alajez NM, Shi W, Yue S, Perez-Ordonez B, $\mathrm{Xu} \mathrm{W}, \mathrm{O}$ 'Sullivan B, Waldron J, Cummings B, et al: Significance of dysregulated metadherin and microRNA-375 in head and neck cancer. Clin Cancer Res 17: 7539-7550, 2011.

25. Wang Z, Hong Z, Gao F and Feng W: Upregulation of microRNA375 is associated with poor prognosis in pediatric acute myeloid leukemia. Mol Cell Biochem 383: 59-65, 2013.

26. Szczyrba J, Nolte E, Wach S, Kremmer E, Stöhr R, Hartmann A, Wieland W, Wullich B and Grässer FA: Downregulation of Sec23A protein by miRNA-375 in prostate carcinoma. Mol Cancer Res 9: 791-800, 2011.

27. Kinoshita T, Yip KW, Spence T and Liu FF: MicroRNAs in extracellular vesicles: Potential cancer biomarkers. J Hum Genet: Jul 7, 2016 (Epub ahead of print). doi: 10.1038/jhg.2016.87.

28. Yonemori K, Kurahara H, Maemura K and Natsugoe S: MicroRNA in pancreatic cancer. J Hum Genet: Jun 2, 2016. (Epub ahead of print). doi: 10.1038/jhg.2016.59.

29. Knäuper V, López-Otin C, Smith B, Knight G and Murphy G: Biochemical characterization of human collagenase-3. J Biol Chem 271: 1544-1550, 1996.

30. Vincenti MP and Brinckerhoff CE: Transcriptional regulation of collagenase (MMP-1, MMP-13) genes in arthritis: Integration of complex signaling pathways for the recruitment of gene-specific transcription factors. Arthritis Res 4: 157-164, 2002.

31. Etoh T, Inoue H, Yoshikawa Y, Barnard GF, Kitano S and Mori M: Increased expression of collagenase-3 (MMP-13) and MT1-MMP in oesophageal cancer is related to cancer aggressiveness. Gut 47: 50-56, 2000

32. Xu N, Zhang L, Meisgen F, Harada M, Heilborn J, Homey B, Grandér D, Ståhle M, Sonkoly E and Pivarcsi A: MicroRNA$125 \mathrm{~b}$ down-regulates matrix metallopeptidase 13 and inhibits cutaneous squamous cell carcinoma cell proliferation, migration, and invasion. J Biol Chem 287: 29899-29908, 2012.

33. Wu D, Ding J, Wang L, Pan H, Zhou Z, Zhou J and Qu P: microRNA-125b inhibits cell migration and invasion by targeting matrix metallopeptidase 13 in bladder cancer. Oncol Lett 5: 829-834, 2013.

34. Osaki M, Takeshita F, Sugimoto Y, Kosaka N, Yamamoto Y, Yoshioka Y, Kobayashi E, Yamada T, Kawai A, Inoue T, et al: MicroRNA-143 regulates human osteosarcoma metastasis by regulating matrix metalloprotease-13 expression. Mol Ther 19: $1123-1130,2011$.

35. Liu J, Mao Y, Zhang D, Hao S, Zhang Z, Li Z and Li B: MiR-143 inhibits tumor cell proliferation and invasion by targeting STAT3 in esophageal squamous cell carcinoma. Cancer Lett 373: 97-108, 2016.

36. Yuen KW, Montpetit B and Hieter P: The kinetochore and cancer: What's the connection? Curr Opin Cell Biol 17: 576-582, 2005.

37. Sagona AP and Stenmark H: Cytokinesis and cancer. FEBS Lett 584: 2652-2661, 2010.

38. Rath $\mathrm{O}$ and Kozielski F: Kinesins and cancer. Nat Rev Cancer 12: 527-539, 2012.

39. Huszar D, Theoclitou ME, Skolnik J and Herbst R: Kinesin motor proteins as targets for cancer therapy. Cancer Metastasis Rev 28: 197-208, 2009.

40. Aytes A, Mitrofanova A, Lefebvre C, Alvarez MJ, CastilloMartin M, Zheng T, Eastham JA, Gopalan A, Pienta KJ, Shen MM, et al: Cross-species regulatory network analysis identifies a synergistic interaction between FOXM1 and CENPF that drives prostate cancer malignancy. Cancer Cell 25: 638-651, 2014.

41. Zhu C, Zhao J, Bibikova M, Leverson JD, Bossy-Wetzel E, Fan JB, Abraham RT and Jiang W: Functional analysis of human microtubule-based motor proteins, the kinesins and dyneins, in mitosis/cytokinesis using RNA interference. Mol Biol Cell 16: 3187-3199, 2005.

42. Corson TW, Zhu CQ, Lau SK, Shepherd FA, Tsao MS and Gallie BL: KIF14 messenger RNA expression is independently prognostic for outcome in lung cancer. Clin Cancer Res 13: 3229-3234, 2007

43. Thériault BL, Pajovic S, Bernardini MQ, Shaw PA and Gallie BL: Kinesin family member 14: An independent prognostic marker and potential therapeutic target for ovarian cancer. Int $\mathbf{J}$ Cancer 130: 1844-1854, 2012 